Удк 633.812:665.52:631.577

\title{
СРАВНИТЕЛЬНЫЙ АНАЛИЗ ЛЕТУЧИХ СОЕДИНЕНИЙ ЭФИРНЫХ МАСЕЛ И ЭТАНОЛЬНЫХ ЭКСТРАКТОВ LAVANDULA HYBRIDA (LAMIACEAE)
}

\author{
() А.Е. Палий", В.Д. Работягов \\ Ордена Трудового Красного Знамени Никитский ботанический сад - \\ Национальный научный центр, Никитский спуск, 52, п.е.т. Никита, Ялта, \\ Республика Крым, 298648 (Россия), e-mail: onlabor@yandex.ru
}

\begin{abstract}
Цель исследования - сравнительный анализ летучих соединений эфирных масел и водно-этанольных экстрактов Lavandula hybrida Rev. сортов «Первенец» и «Темп» для определения перспективы их практического использования.

Эфирное масло извлекали из воздушно-сухого растительного сырья методом гидродистилляции по Гинзбергу. Экстракцию проводили водным этанолом. Компонентный состав летучих веществ эфирных масел и этанольных экстрактов определяли методом газожидкостной хроматографии с масс-спектрометрическим детектированием.

Проведен сравнительный анализ компонентного состава и содержания летучих соединений эфирного масла и водно-этанольных экстрактов двух сортов L. hybrida селекции Никитского ботанического сада. В эфирном масле и экстракте из сорта «Первенец» выявлено повышенное содержание нежелательных компонентов: камфоры и 1,8цинеола. Эфирное масло и экстракт из сорта «Темп» отличаются высокой концентрацией линалилацетата и низкой камфоры и 1,8-цинеола. Эфирное масло и экстракт из L. hybrida сорта «Темп» являются перспективными для использования в косметике и парфюмерии.

Ключевые слова: Lavandula hybrida, эфирное масло, водно-этанольный экстракт, линалилацетат, линалоол, камфора, 1,8-цинеол.
\end{abstract}

Работа выполнена при поддержке Российского научного фонда (проект №14-5000079).

\section{Введение}

Лавандин Lavandula hybrida Rev. (Lamiaceae) - межвидовой гибрид, полученный в результате естественного или искусственного скрещивания лаванды узколистной (Lavandula angustifolia Mill.) и лаванды широколистной (Lavandula latifolia Medie.). Является перспективной эфирно-масличной культурой, отличающейся высокой урожайностью и содержанием эфирного масла. Эфирное масло лавандина имеет цветочно-фруктовое направление запаха, его качество определяется содержащимися в нем терпеновыми сложными эфирами (линалилацетат, геранилацетат, борнилацетат, терпенилацетат) и терпеновыми спиртами (линалоол, гераниол, терпениол). Но если в масле присутствуют высокие концентрации цинеола, борнеола и камфоры, то оно приобретает неприятный кислокамфорный запах [1-3].

Известно, что на качественный и количественный составы биологически активных веществ в расте-

Палий Анфиса Евгеньевна - заведующая лабораторией биохимии отдела технических культур и биологически активных веществ, кандидат биологических наук, e-mail: onlabor@yandex.ru

Работягов Валерий Дмитриевич - главный научный сотрудник лаборатории ароматических и лекарственных растений отдела технических культур и биологически активных веществ, доктор биологических наук, профессор, e-mail: onlabor@yandex.ru ниях, к которым относятся и летучие компоненты эфирных масел, значительное влияние оказывают его генетическое происхождение и условия произрастания, кроме того, немаловажную роль имеют способы извлечения этих веществ из растительного сырья. Так, нативные экстракты, не подвергшиеся термообработке и воздействию процессов разделения и очистки, имеют, как правило, более

\footnotetext{
* Автор, с которым следует вести переписку.
} 
высокую биологическую активность за счет действия всего комплекса физиологически активных веществ растения [4]. В связи с этим актуально исследование особенностей перехода летучих соединений лавандина в этанольный экстракт.

В Государственном бюджетном учреждении Республики Крым «Ордена Трудового Красного Знамени Никитском ботаническом саду - Национальном научном центре» (ГБУ РК «НБС - ННЦ») ведутся многолетние работы по интродукции и селекции лавандина, в результате которых получен целый ряд хозяйственно ценных сортов, в том числе «Первенец» и новый сорт «Темп» [5].

Цель настоящего исследования - провести сравнительный анализ летучих соединений эфирных масел и водно-этанольных экстрактов лавандина сортов «Первенец» и «Темп» для определения перспективы их практического использования.

\section{Экспериментальная часть}

Объектами исследования являлись соцветия двух сортов лавандина «Первенец» и «Темп» селекции ГБУ РК «НБС - ННЦ». Растительное сырье собирали на коллекционных участках лаборатории ароматических и лекарственных растений ГБУ РК «НБС - ННЦ» (п.г.т. Никита, Ялта, Республика Крым) в фазе массового цветения в июле 2014 г.

Сорт «Первенец» выведен методом межвидовой гибридизации лаванды узколистной с лавандой широколистной. Куст среднекомпактный, соцветие рыхлое, длиной 6-8 см (без ложной мутовки), с восемьюдевятью мутовками. Чашечка средней величины, цилиндрическая, зелено-фиолетовая, сильноопушенная, на длинной цветоножке. Листья ярко-зеленые, узколинейные, слабоопушенные, длинной 5-7, шириной 0,5-0,8 см. Массовое цветение наступает на 2-3 недели позднее, чем у районированных сортов лаванды.

Сорт «Темп» получен методом межвидовой гибридизации лаванды узколистной (сорт «Рекорд») с лавандой широколистной. Растения компактной формы, крупных размеров, высотой 85 см, диаметром 100 см. Соцветие плотное, прерывистое с 9-10 мутовками, цветок темно-фиолетовой окраски. Устойчив к поражению болезнями, зимостойкий и засухоустойчивый, отличается высокой урожайностью соцветий.

Эфирное масло извлекали из мелкоизрубленного воздушно-сухого растительного сырья методом гидродистилляции по Гинзбергу, с дальнейшим перерасчетом на сухую массу [6]. Время отгонки эфирного масла - 1 ч.

Этанольные экстракты (далее - экстракты) готовили из мелкоизрубленного воздушно-сухого растительного сырья. Экстракцию проводили 50\%-ным этиловым спиртом при соотношении сырья и экстрагента $1: 10$ настаиванием в течение 10 суток при комнатной температуре.

Компонентный состав летучих веществ эфирных масел и этанольных экстрактов определяли методом газожидкостной хроматографии на хроматографе Agilent Technology 6890 с масс-спектрометрическим детектором 5973. Колонка HР-1 длиной 30 м; внутренний диаметр - 0,25 мм. Температура термостата программировалась от 50 до $250^{\circ} \mathrm{C}$ со скоростью $4{ }^{\circ} \mathrm{C} /$ мин. Температура инжектора $-250{ }^{\circ} \mathrm{C}$. Газ-носитель гелий, скорость потока $1 \mathrm{~cm}^{3} /$ мин. Перенос от газового хроматографа к масс-спектрометрическому детектору прогревался до $230{ }^{\circ} \mathrm{C}$. Температура источника поддерживалась на уровне $200{ }^{\circ} \mathrm{C}$. Электронная ионизация проводилась при 70 эВ в ранжировке масс $\mathrm{m} / \mathrm{z}$ от 29 до 450. Идентификация выполнялась на основе сравнения полученных масс-спектров с данными комбинированной библиотеки NIST05-WILEY.

\section{Обсуждение результатов}

В результате проведенных исследований установлено, что урожайность лавандина сорта «Первенец» составляла 65-70 ц/г, массовая доля эфирного масла из соцветий была 2,9\% от сырой массы, в пересчете на сухое сырье $-2,5 \%$. При хроматографическом разделении эфирного масла обнаружено 25 компонентов, из них 24 идентифицировано (табл.). Концентрация летучих соединений в экстракте равнялась 770,7 мг/100 г в пересчете на сухое растительное сырье. В составе летучей фракции выявлено 30 компонентов, из которых 28 идентифицировано.

Урожайность сорта «Темп» превышала более чем на $50 \%$ урожайность «Первенца» и составляла 104 ц/га. Массовая доля эфирного масла из соцветий достигала 2,7\% от сырой массы, в пересчете на сухое сырье $-6,8 \%$. В эфирном масле присутствовали 34 компонента, из них 31 был идентифицирован. Концентрация летучих соединений в экстракте данного сорта равнялась 690,0 мг/100 г. В составе летучей фракции обнаружены 28 компонентов, из них 25 идентифицированы. 
Состав летучих соединений эфирных масел и этанольных экстрактов Lavandula hybrida

\begin{tabular}{|c|c|c|c|c|}
\hline \multirow{3}{*}{ Компонент } & \multicolumn{4}{|c|}{ Массовая доля, \% } \\
\hline & \multicolumn{2}{|c|}{ «Первенец» } & \multicolumn{2}{|c|}{ «Темп» } \\
\hline & эфирное масло & экстракт & эфирное масло & экстракт \\
\hline \multicolumn{5}{|c|}{ Монотерпены } \\
\hline \multicolumn{5}{|c|}{ Ациклические монотерпены } \\
\hline$\beta$-мирцен & 0,05 & 0,06 & 0,98 & 0,18 \\
\hline транс-оцимен & - & 0,09 & 4,05 & 2,12 \\
\hline ичис-оцимен & - & - & 0,55 & - \\
\hline \multicolumn{5}{|c|}{ Моноциклические монотерпены } \\
\hline Фелландрен & - & - & 0,06 & - \\
\hline Лимонен & 0,53 & 0,16 & 1,05 & 1,00 \\
\hline$\gamma$-терпинен & - & - & 0,15 & 0,66 \\
\hline$\alpha$-терпинолен & - & - & 0,13 & 0,73 \\
\hline \multicolumn{5}{|c|}{ Бициклические монотерпены } \\
\hline$\alpha$-туйен & 0,02 & 0,06 & 0,09 & - \\
\hline$\alpha$-пинен & 0,05 & 0,01 & 0,46 & - \\
\hline Камфен & 0,08 & 0,04 & 0,17 & 0,24 \\
\hline Сабинен & 0,06 & 0,04 & 0,25 & - \\
\hline$\beta$-пинен & 0,07 & 0,01 & 0,51 & - \\
\hline$\Delta^{3}$-карен & - & - & 0,37 & 0,05 \\
\hline Сумма монотерпенов & 0,81 & 0,47 & 8,82 & 4,98 \\
\hline \multicolumn{5}{|c|}{ Сесквитерпены } \\
\hline транс- $\beta$-кариофиллен & 0,39 & 0,86 & 2,51 & 0,51 \\
\hline Фарнезен & - & - & 2,58 & 0,58 \\
\hline Сумма сесквитерпенов & 0,39 & 0,86 & 5,09 & 1,09 \\
\hline Сумма терпенов & 1,20 & 1,33 & 13,91 & 6,07 \\
\hline \multicolumn{5}{|c|}{ Производные терпенов } \\
\hline \multicolumn{5}{|c|}{ Монотерпеновые спирты } \\
\hline Линалоол & 37,33 & 33,79 & 41,82 & 40,42 \\
\hline Терпинен-4-ол & 1,38 & 0,83 & 2,22 & 2,21 \\
\hline$n$-ментен-8-ол & - & - & 0,18 & 0,08 \\
\hline Изоборнеол & 4,57 & 2,76 & 2,20 & 2,24 \\
\hline \multicolumn{5}{|c|}{ Монотерпеновые оксиды } \\
\hline 1,8-цинеол & 4,85 & 6,94 & 6,72 & 6,85 \\
\hline цчис-линалоолоксид & 3,06 & 2,57 & 0,16 & 1,18 \\
\hline транс-линалоолоксид & 2,91 & 2,64 & 0,05 & 0,45 \\
\hline \multicolumn{5}{|c|}{ Монотерпеновые кетонь } \\
\hline Камфора & 13,96 & 12,55 & 2,31 & 3,02 \\
\hline \multicolumn{5}{|c|}{ Монотерпеновые сложные эфирьл } \\
\hline Линалилацетат & 23,42 & 22,34 & 27,85 & 25,34 \\
\hline Лавандулилацетат & 0,69 & 0,15 & 0,08 & \\
\hline Нерилацетат & 1,19 & 1,26 & 0,11 & 0,15 \\
\hline Геранилацетат & 1,85 & 0,53 & 0,37 & 0,72 \\
\hline \multicolumn{5}{|c|}{ Сесквитерпеновые оксиды } \\
\hline Кариофиленоксид & 2,31 & 3,52 & - & 0,32 \\
\hline \multicolumn{5}{|c|}{ Дитерпеновые спирты } \\
\hline Фитол & - & 2,35 & - & 3,36 \\
\hline Сумма производных терпенов & 97,52 & 92,23 & 84,07 & 86,34 \\
\hline \multicolumn{5}{|c|}{ Нетерпеновые соединения } \\
\hline$n$-цимен & 0,15 & 0,20 & 0,11 & 0,32 \\
\hline Октилацетат & 0,52 & 0,33 & 1,04 & 0,85 \\
\hline Гексил 2-метилбутират & 0,31 & 0,08 & 0,23 & - \\
\hline Гексилацетат & 0,12 & - & 0,38 & 0,56 \\
\hline Этилпальмитат & - & 1,68 & - & 2,12 \\
\hline Этиллинолеат & - & 0,27 & - & 0,04 \\
\hline Этиллиноленат & - & 1,18 & - & 2,45 \\
\hline Сумма нетерпеновых соединений & 1,10 & 3,74 & 1,76 & 6,34 \\
\hline $\begin{array}{l}\text { Количественное содержание иден- } \\
\text { тифицированных компонентов }\end{array}$ & 99,82 & 97,30 & 99,74 & 98,75 \\
\hline
\end{tabular}


Сравнительный анализ компонентного состава летучих веществ двух сортов лавандина показал, что основным компонентом как эфирных масел, так и экстрактов являлся линалоол, его массовая доля составляла от 33,8\% (экстракт «Первенца») до 41,8\% (эфирное мало «Темпа»). Содержание сложных эфиров монотерпенов в эфирном масле сорта «Первенец» составляло более $27 \%$, в том числе наиболее ценного эфира линалилацетата $-23,4 \%$. В эфирном масле сорта «Темп» концентрацией сложных эфиров монотерпенов и линалилацетата была выше - 28,4 и 27,9\% соответственно. Экстракты изучаемых сортов отличались более низким содержанием фракции сложных эфиров: 24,3 («Первенец») и 26,2\% («Темп»).

Важным показателем качества эфирного масла лавандина является суммарное содержание 1,8-цинеола и камфоры [3]. Для эфирного масла сорта «Перевенец» оно составляло 18,8\%, для сорта «Темп»$9,0 \%$. В экстрактах - 19,5 и 9,9\% соответственно.

\section{Bыводbl}

Анализ компонентного состава летучих веществ эфирных масел и экстрактов двух сортов лавандина показал, что массовая доля камфоры и 1,8-цинеола в составе летучих соединений сорта «Первенец» превышает $18 \%$, что значительно ухудшает качество данных продуктов переработки растительного сырья. В то же время эфирное масло и экстракт из лавандина сорта «Темп» содержат около $10 \%$ камфоры и 1,8-цинеола, и отличаются высокими концентрациями линалоола до $41 \%$ и сложных эфиров монотерпенов до $28 \%$, в частности линалилацетата до $28 \%$. По компонентному составу эфирное масло сорта «Темп» близко к эфирному маслу лавандина французского коммерческого сорта «Grosso» [7]. Таким образом, эфирное масло и экстракт из лавандина сорта «Темп» являются перспективными для использования в косметике и парфюмерии, кроме того, эфирное масло данного сорта можно также использовать для извлечения натурального линалоола.

\section{Список литературы}

1. Войткевич С.А. 865 душистых веществ для парфюмерии и бытовой химии. М., 1994. 594. с.

2. Машанов В.И., Андреева Н.Ф., Машанова Н.С. Новые эфирномасличные культуры: Справочное издание. Симферополь, 1988. $160 \mathrm{c}$.

3. Lis-Balchin M. Lavander. The Genus Lavandula. Medicinal and Aromatic Plants- Industrial Profiles. London, 2002. $268 \mathrm{p}$.

4. Зилфикаров И.Н. Дитерпены и полифенолы шалфея лекарственного: перспективы медицинского применения (обзор литературы) // Вестник Санкт-Петербургского университета. Сер. 11. 2007. Вып. 3. С. 149-158.

5. Работягов В.Д., Хлыпенко Л.А., Бакова Н.Н., Машанов В.И. Аннотированный каталог видов и сортов эфирномасличных, пряно-ароматических и пищевых растений коллекции Никитского ботанического сада. Ялта, 2007. $48 \mathrm{c}$.

6. Государственная фармакопея СССР. М., 1987. Вып. 1.

7. Barocelli E., Calcina F., Chiavarini M., Impicciatore M., Bruni R., Bianchi A., Ballabeni V. Antinociceptive and gastroprotective effects of inhaled and orally administered Lavandula hybrida Reverchon 'Grosso' essential oil // Life Science. 2004. Vol. 76. Pp. 213-223. 
Paliy A.E. , Rabotyagov V.D. COMPARATIVE ANALYSIS OF VOLATILE COMPOUNDS OF LAVANDULA HYBRIDA (LAMIACEAE) ESSENTIAL OILS AND ETHANOL EXTRACT

Nikitsky Botanical gardens, Nikitskii spusk, 52, Urban-type settlement Nikita, Yalta, Republic of Crimea, 298648

(Russia),e-mail: onlabor@yandex.ru

The research objective is a comparative analysis of volatile compounds of Lavandula hybrida Rev. essential oils and water-ethanol extracts (sorts «Pervenets» and «Temp») in order to determine prospects for their practical use.

Essential oil was extracted from the air-dry plant raw materials by hydro distillation by Ginsberg. Extraction was carried out with aqueous ethanol. Component composition of essential oils volatiles and ethanol extracts was determined by gasliquid chromatography with mass spectrometric detection.

The comparative analysis of component composition and content of volatile compounds produced from the essential oil and water-ethanol extracts of two L. hybrid sorts (introduced in Nikitsky Botanical gardens) has been conducted. The high content of undesirable components was revealed in essential oils and extracts of sort Pervenets: camphor and 1,8-cineole. Essential oils and extracts of sort Temp are characterized by high concentration of linalyl acetate, low concentration of camphor and 1,8cineole. Essential oils and extracts of sort Temp are perspective in cosmetic and perfume areas.

Keywords: Lavandula hybrida, essential oil, water-ethanol extract, linalyl acetate, linalool, camphor, 1,8-cineole.

\section{References}

1. Voitkevich S.A. 865 dushistykh veshchestv dlia parfiumerii i bytovoi khimii. [865 fragrances for perfumes and household products]. Moscow, 1994, 594 p. (in Russ.).

2. Mashanov V.I., Andreeva N.F., Mashanova N.S. Novye efirnomaslichnye kul'tury: Spravochnoe izdanie. [New essential oil crops: Reference books]. Simferopol, 1988, 160 p. (in Russ.).

3. Lis-Balchin M. Lavander. The Genus Lavandula. Medicinal and Aromatic Plants-Industrial Profiles. London, 2002. $268 \mathrm{p}$.

4. Zilfikarov I.N. Vestnik Sankt-Peterburgskogo universiteta. Series 11, 2007, no. 3, pp. 149-158. (in Russ.).

5. Rabotiagov V.D., Khlypenko L.A., Bakova N.N., Mashanov V.I. Annotirovannyi katalog vidov i sortov efirnomaslichnykh, priano-aromaticheskikh i pishchevykh rastenii kollektsii Nikitskogo botanicheskogo sada. [Annotated catalog of species and varieties of essential oil, Aromatic plants and food Nikitsky Botanical Garden]. Yalta, 2007, 48 p. (in Russ.).

6. Gosudarstvennaia farmakopeia SSSR. [State Pharmacopoeia of the USSR]. Moscow, 1987, issue 1. (in Russ.).

7. Barocelli E., Calcina F., Chiavarini M., Impicciatore M., Bruni R., Bianchi A., Ballabeni V. Life Science, 2004, vol. 76, pp. 213-223.

Received May 15, 2015

Revised May 28, 2015

\footnotetext{
* Corresponding author.
} 
